\title{
Analysis of methodological bases of energy- economic assessment of agricultural technologies and projects
}

\author{
Yuri Shirokov ${ }^{1, *}$ and Valery Tikhnenko ${ }^{1}$ \\ ${ }^{1}$ Russian state agrarian University-Moscow agricultural Academy K. A. Timiryazeva, 49, \\ Timiryazevskaya str., 127550, Moscow, Russia
}

\begin{abstract}
The article shows that the urgency of the fuel and energy problem determines the need for rational energy consumption in all sectors of the economy, including agriculture. A comprehensive cross-sectoral approach is needed to address the issues of systematic management of energy saving in agriculture and to justify rational measures of economic support for the introduction of energy-saving technologies, machines, and projects on the part of the state. It is shown that the energy-economic (bioenergetic) estimation method meets these requirements.. The main advantage of the energy-economic assessment is that its application makes it possible to compare in single units of measurement (regardless of the historical period or the state, the current market situation) the costs of cultivating plants or servicing animals with the results of production and is mainly of national strategic importance. An approach to improving the methodology of energyeconomic assessment of agricultural technologies and projects when using renewable energy sources in technological processes is presented. It is proved that in order to ensure the reliability of the energy-economic assessment in connection with the constant technological and organizational changes and the digitalization of technology and the economy, it is necessary to continue research in the direction of improving the methodology for assessing, clarifying and regularly updating energy equivalents.
\end{abstract}

\section{Introduction}

Russian agriculture consumes an average of 3.3 -3.5 million tons of diesel fuel annually. Due to the climatic features of most regions of the country, more than 1 million tons of fuel is spent on heating rooms and drying agricultural products. The total energy costs for the production of 1 ton of conventional grain unit in Russia in comparison with the United States are more than 5 times higher [1-5]. This alone significantly reduces the potential for competitiveness of agricultural products of Russian farmers.

And the constant increase in the cost of energy carriers further increases the share of costs for these resources in the structure of the cost of the final product. Accordingly, the economic

\footnotetext{
* Corresponding author: shirokov001@mail.ru
} 
effect of technological, managerial and other improvements is offset by the growing cost of energy carriers. This situation is the main reason for the active introduction of energy-saving technologies and renewable energy sources by developed countries in their agricultural production [6-9].

In the Russian Federation, due to many reasons, only certain elements of energy-efficient solutions are used, which have become commonplace in the agricultural production of many countries. At the same time, as rightly noted in the State Program of the Russian Federation "Energy Saving and Energy Efficiency Improvement for the period up to 2020" "...In these conditions, the main way to maintain competitiveness is to reduce costs (if possible) for those items in which there is a significant lag behind the level of international producers. In Russian agriculture, such an item is primarily energy costs. All this requires a revision of scientific views, principles of organization and quality of work on energy conservation of both agriculture as a whole and its individual enterprises. A comprehensive cross-sectoral approach is needed to address the issues of systematic management of energy saving in agriculture." And measures are needed to provide economic support for the introduction of energy-saving technologies, machines, and projects by the state [9-11].

For example, in the United States, realizing that farmers will not invest in energy saving on their own, a number of laws and state programs have been adopted for state support since 1998, aimed at serious economic support for the introduction of energy-saving technologies in agriculture. In particular, the Energy Policy Act of 2005, which provided financial assistance to bioethanol producers in the form of subsidies, tax incentives and import duties. The Food, Conservation, and Energy Act of 2008 - Farm Bill provided financial support for the development of renewable energy production in rural areas [12-15].

However, the state structures responsible for making decisions on the types and level of economic incentives for energy saving should clearly represent the full energy efficiency of technologies, i.e. the actual energy savings not only in agricultural production, but in all commodity chains and in the life cycle of equipment from the production of energy carriers, machines and technological lines, construction of buildings and structures, etc., to the implementation of field technological operations, operation and disposal of machines and equipment.

Therefore, at the state level, a comprehensive intersectoral approach to the justification and solution of issues of system management of energy saving is necessary. In this regard, there is a need for a reliable justification of the directions of reducing energy consumption at various levels: at the state level - in order to develop an effective resource-saving policy and develop measures to support the most energy-efficient areas; at the level of research and design organizations - in order to assess the energy efficiency of machines, technologies, projects; at the level of an agricultural enterprise - in order to reduce the cost of production and increase the competitiveness of products. And for error-free decision-making at each level of management, it is necessary to have appropriate methods for assessing real energy efficiency.

The fundamentals of such a methodology have been established, but they need to be improved, taking into account organizational, technological and technical changes that have led to the transfer of a significant part of energy consumption from the field to the workshops of factories and the use of renewable energy sources not only in field technologies, but throughout the entire industrial production chain.

The aim of the work is to improve the methodology of energy-economic assessment of agricultural technologies and projects for the system management of energy saving in agriculture. 


\section{Materials and methods}

It is methodically fair to use well-known rules when measuring the efficiency of energy consumption: a) reflect the co-measurement of costs and effects, b) have qualitative uniformity and quantitative comparability. At the same time, the "effect identity rule"must be taken into account. Its essence is that the compared options should perform identical tasks for all the compared parameters. And, finally, the rule " bringing design options to the overall effect [14-16].

The methodological basis of our work is a systematic analysis, specified in the framework of the approach to assessing the efficiency of energy use in the production of agricultural products, taking into account its costs in all related sectors of the economy.

The main production process in agriculture is the use of the ability of plants to absorb the energy of photons of sunlight (range from 380 to $720 \mathrm{~nm}$ ) during photosynthesis and form organic matter from carbon dioxide of air and water under certain anthropogenic influences - in crop production or the process of converting synthesized organic matter of plants in animal organisms into animal products - in animal husbandry. The rationality of energy consumption can be assessed by comparing the amount of energy accumulated in crop or animal products with the total energy spent on production. This method is called "the method of energy-economic assessment" or " the method of bioenergetic assessment "(Bazarov E. I., Novikov Yu. F., Shirokov Yu. A. et al. 1982-1985)

The authors of the methodology proceeded from the fact that the total energy (total energy intensity) includes two main types of energy spent: direct (in the form of energy resources for the implementation of the technological process and the energy of the living labor of participants in the agricultural production process) and materialized (energy spent on the production of means of production at all stages of the technological chain, including energy consumption for the extraction, transportation, processing of minerals and the production of energy carriers, fertilizers, plant protection products, materials, parts, If direct energy costs are fairly easy to determine, then the assessment of materialized energy costs is difficult due to the significant branching of technological and transport and logistics chains and the complexity of access to primary information of enterprises of various forms of ownership.

To determine the value of the cost of past, materialized energy, two approaches are used: direct calculation and use of the coefficients of total energy costs per accounting unit of raw materials or finished products in $\mathrm{kg}, \mathrm{m} 3$, etc. - energy equivalents.

An indicator of energy efficiency is the coefficient of bioenergetic efficiency $\mathrm{K}_{\mathrm{be}}$, which is equal to the ratio of the energy output accumulated in the economically useful part of the $E_{h}$ crop $(J)$ to the sum of the photosynthetically active radiation (FAR) of the Sun coming per unit area of the crop for the growing season of the $E_{s}(J)$ and the total energy spent on maintenance of the crops of the same crop in this area during the same period of the year $E_{a}$ $(\mathrm{J})$ :

$$
\mathrm{Kbe}_{\mathrm{p} 1}=\sum \mathrm{E}_{\mathrm{hp}} /\left(\mathrm{E}_{\mathrm{sp}}+\sum \mathrm{E}_{\mathrm{ap}}\right) .
$$

That is, here it is estimated how the energy accumulated in the crop (assimilated by plants) relates to the amount of solar energy coming to the cultivated area during the growing season in a given climate zone and the energy of resources that help plants effectively assimilate solar energy, ensuring the yield [2].

A close version of the assessment in the US and Canada: here the bioenergy efficiency coefficient is proposed, calculated as the ratio of energy output in production $(\mathrm{Eu})$ minus total energy costs $\left(\mathrm{E}_{\mathrm{ap}}\right)$ to insolation $\left(\mathrm{E}_{\mathrm{sp}}\right)$ :

$$
\mathrm{K}_{\mathrm{bep} 2}=\left(\mathrm{E}_{\mathrm{hp}}-\sum \mathrm{E}_{\mathrm{ap}}\right) / \mathrm{E}_{\mathrm{sp}}
$$


Due to the fact that the solar energy involved in the process of photosynthesis differs in different zones of the country, the calculation of the Kbe value is important when zoning agriculture, when it is necessary to compare the efficiency of the placement of agricultural crops on the territory of the country and justify the appropriate recommendations to agricultural producers, or to stimulate the effective placement of agricultural crops by economic methods. Also, the use of formula (1) is advisable when assessing the genetic potential and prospects for cultivation (zoning) of agricultural varieties.

In comparative calculations, it should be taken into account that photosynthetically active solar energy, which reaches one hectare of land for a 3-month growing season, depends on the region of the country and ranges from 8 to 35 billion rubles. $\mathrm{kJ} b$ (initial data can be obtained from the regional meteorological services). Plants in the process of photosynthesis usually absorb from 0.8 to $1.5 \%$ of this energy, rarely up to $5 \%$.

For practical calculations of the assessment of the efficiency of the use of total energy costs in the production of agricultural products (the total energy intensity of agricultural production) in order to select energy-efficient machines, agricultural technologies and projects, a method is proposed that estimates the value of the bioenergy efficiency coefficient of $\mathrm{K}_{\text {bes: }}$ the efficiency of total energy costs for the cultivation of $\mathrm{E}_{\text {ar }}$ plants by comparing them with the energy output in the resulting crop of $\mathrm{E}_{\mathrm{h}}$ (without taking into account the level of insolation in the region).

The result of the assessment: determination of the value of the bioenergy efficiency coefficient-an indicator that establishes the ratio between the solar energy accumulated in the agricultural product collected from a unit of area-Eh and the total energy of Ea, including the energy of energy carriers spent on the entire cycle of field work on a given area, the share of the past energy transferred to a unit of area, embodied in the means of production and the share of the energy of the living labor of agricultural enterprise employees involved in the cultivation of plants on a given unit of area:

$$
\mathrm{K}_{\text {bep }}=\sum \mathrm{E}_{\mathrm{hp}} / \sum \mathrm{E}_{\mathrm{ap}}
$$

As noted above, the total energy of the Eap is defined as the sum of the energy costs of energy carriers in the technological process of crop production( Er), the energy of the living labor of the participants in the process $\left(\mathrm{E}_{\mathrm{w}}\right)$ and the sum of the costs of past energy embodied in the means of production of the Ee:

$$
\begin{gathered}
\mathrm{E}_{\mathrm{a}}=\sum \mathrm{E}_{\mathrm{f}}+\sum \mathrm{E}_{\mathrm{w}}+\sum \mathrm{E}_{\mathrm{e}}, \\
\mathrm{E}_{\mathrm{\Pi}}=\sum \mathrm{M}_{\mathrm{i}} \times \varepsilon_{\mathrm{e}},
\end{gathered}
$$

where $\mathrm{Mi}$ is the mass of $\mathrm{i}$-th products used in agricultural production, $\mathrm{t}$;

$\mathcal{E} \mathrm{e}_{\mathrm{i}}$ - energy equivalent (the content of past energy in the unit of the i-th product), $\mathrm{MJ} / \mathrm{kg}$, $\mathrm{MJ} / \mathrm{m} 3$. .

When using the method of energy-economic assessment, it is necessary to pay attention to the fact that the work on the calculation of energy equivalents EEi was performed in the 80 -ies of the last century. A number of assumptions were used in the calculations, for example, the average energy "cost" of a ton of tractor-35 GJ, tons of agricultural machinery30 GJ, cubic meters of buildings-55 GJ, tons of fertilizers: nitrogen - 86; phosphorous - 12; potash-8, tons of diesel fuel-79.5 GJ, thousand kW.h of electricity - 12, thousand people. $h$. live labor - $43 \mathrm{GJ}$, etc., which made it possible to make the results of calculations of the coefficients of bioenergetic efficiency of specific technologies quite comparable.

The equivalents for fixed assets are calculated taking into account the fact that they annually transfer a part of the total energy to the products in proportion to the service life and time for cultivation of the crop.. Live labor equivalents take into account the cost of muscle 
strength and intellectual energy, taking into account professional training, the complexity of the work, as well as the cost of energy for life support. Therefore, for example, the release of one tractor driver due to the increase in labor productivity when using new equipment or technology reduces the energy intensity of the process not only by the amount of his personal energy costs, but also the energy costs for his public utilities (heat, electricity, gas, etc.).

Further calculation of the total energy is carried out on the basis of the energy equivalents EEi. The more reliable and thorough the calculation of energy equivalents is, the more accurate the result of calculating the coefficients of bioenergy efficiency and energyeconomic assessment and the more reasonable the management decisions made on the basis of such calculations.

Let's look at a variant of such an energy-economic assessment on the example of a new type of biofuel for boiler and turbo-generator plants: a homogenized cellulose-oil mixture based on the cavitation homogenization of rapeseed oil and (or) furnace (diesel) fuel with flour from rapeseed biomass (and other field waste: grain straw, etc.) and (partially) water.

Now the yield of rapeseed seeds in the Russian Federation is from 1.8 to 4.0 tons per hectare. The yield of rapeseed oil is 0.7-1.8 tons per hectare (26000-67000 MJ of energy). A significant part of the biomass of rapeseed-3.0-4.5 tons of dry matter per hectare (stems, pods, leaves) - and it stores the energy of the sun at the level of 43,000 - 65,000 MJ-remains in the field. The total energy costs for the production of 1 ton of natural-dried rapeseed grass flour will not exceed 3,500 MJ, the energy content in one ton of rapeseed grass flour will be about 11,000-14,000 MJ, i.e., the energy transformation coefficient of the Kbpp is from 3.14 to 4.0.

The constant improvement of technologies in mechanical engineering, chemical production, production of building materials and other resources, as well as the changing costs of extraction and production of each type of energy carriers and raw materials, require constant clarification of the quantitative values of energy equivalents. This is confirmed by the statistical report "Energy Efficiency Indicators 2019": the amount of energy used to produce a unit of GDP, also called the energy intensity of the economy (TPE/GDP), declined globally by $35 \%$ between 1990 and 2017

The methodology needs some correction, taking into account the fact that in modern agricultural production, more and more resources and labor of past periods are used, and the importance of these material agents is gradually increasing. For example, it is enough to visually compare the machine-tractor units of the period of development of energy equivalents (Fig. 1.) and the modern sowing complex (Fig. 2.) to see significant changes that should be reflected in the applied energy equivalents.

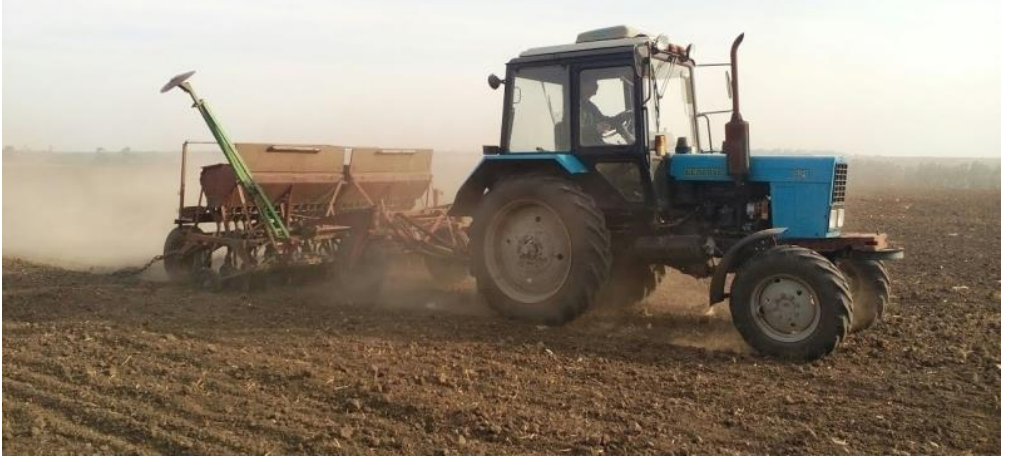

Fig. 1. Seeding machine-tractor unit during the development of energy equivalents. 


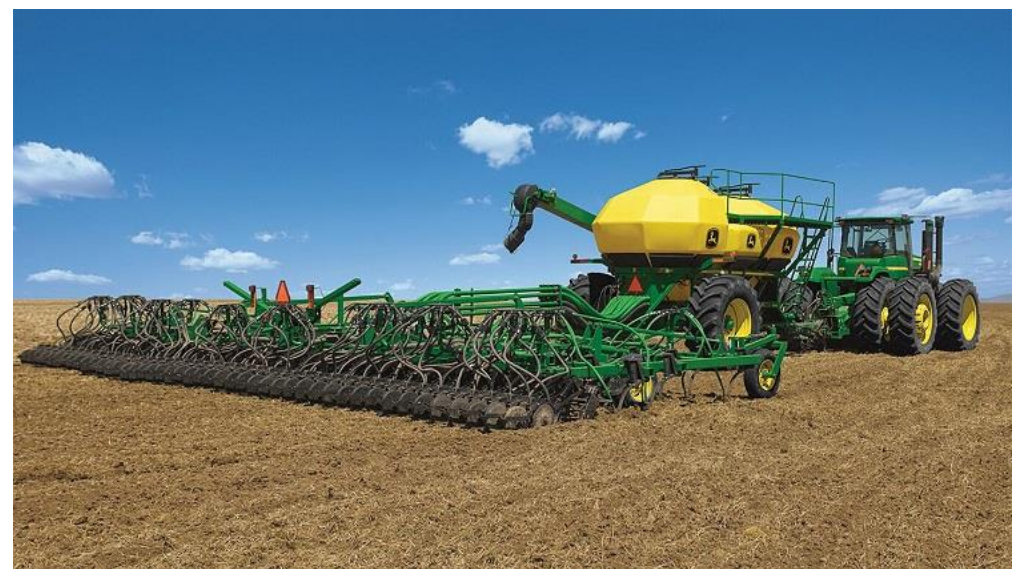

Fig. 2. Modern seeding machine and tractor unit.

And the computerization of machines and production processes further increases the cost of materialized energy. Processes that until recently were performed by the operator (tractor driver-machinist) at the expense of their own energy costs (the energy of living labor), they are performed to a large extent already at the expense of energy embodied in computer and satellite systems (Fig. 3.). But at the same time, the intenconsumption of

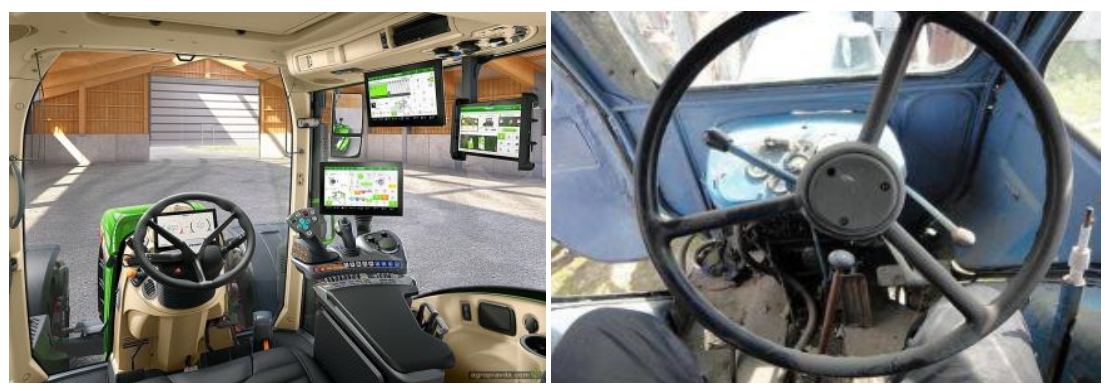

Fig. 3. Changes in the machine-tractor unit control systems.

To provide methodological support for future adjustments, "Methodological recommendations for the justification of energy equivalents for machinery and equipment for agro-industrial production" and "Methodological recommendations for the justification of energy equivalents for rural construction" were developed (M. VASKHNIL, 1984). It was planned that further research teams will be engaged not only in the application of the developed methods, but also in their improvement and refinement, taking into account changes in technologies in mechanical engineering, and concepts in crop and animal husbandry technologies. However, in the calculations of many researchers, dissertations mainly use outdated indicators without correction for the changes that have occurred.

To assess absolute energy efficiency, it is necessary to take into account all elements of total energy costs without exception, which can present great difficulties due to access to information for calculating energy equivalents. A. S. Mindrin suggests using an integrated economic and energy method for evaluating production. To do this, it is necessary to calculate the energy equivalent of the ruble and the cost estimate of the unit of energy. The energy equivalent of the ruble $\mathcal{E P}, \mathrm{J} / \mathrm{rub}$, is determined by the formula 6 :

$$
\varepsilon_{\mathrm{r}}=\mathrm{E}_{\mathrm{hp}} / \mathrm{C}_{\mathrm{mp}} \times \eta_{\mathrm{t}}
$$


where $\mathrm{E}_{\mathrm{hp}}$ is the use of energy resources in the current (past) year, $\mathrm{J}$;

$\mathrm{C}_{\mathrm{mp}}$ - net material product, rub.;

$\mathrm{nt}$ - Cmp production index by economic sector $\mathrm{t}$.

A similar approach to the calculation of energy equivalents is proposed in the work of $\mathrm{N}$. Samoilova.

However, there is a risk that going into the revaluation of energy equivalents through the cost of resources (and here the influence of market conditions, the volatility of the ruble, the contribution of commercial intermediaries, etc.) will lead to the same errors as a direct assessment in monetary terms. Therefore, for the purposes of the national assessment, it is necessary to return to the equivalents through constant energies. the tractor driver-driver did not decrease.physical parameters: energy consumption per $\mathrm{kg}(\mathrm{t})$ (metal, liquid fuel, fertilizers, seeds, etc.), m3 (gas, premises, etc.), etc.

The problem is that when calculating energy equivalents, many authors do not take into account that machines, buildings and structures serve for several years, and often participate in the production of several crops. Accordingly, they transfer only a part of the energy, which should be taken into account.

In the methods of energy economic assessment, it is necessary to take into account the significant increase in the share of renewable energy sources in the production process. In this regard, when calculating the total energy of the Ea, it is necessary to exclude the share of spent renewable energy (solar, wind, biomass energy, etc.) used in the technological process of the Er. It is also necessary to clarify the resources of imported origin. For the purposes of the national assessment of the efficiency of energy saving, it is necessary to exclude the costs of embodied energy in imported products (machinery, equipment, seeds, fertilizers, plant protection products, etc.) when calculating the total energy intensity of agricultural production. This distinguishes the methodology for evaluating energy efficiency from the calculation of economic efficiency. In this case, there is a national egoism: energy savings within the country due to the interstate division of labor (there is a contradiction with the transition to import substitution).

Therefore, the value of the Kbe should be clarified:

$$
\mathrm{Kbe}=\mathrm{E}_{\mathrm{h}} /\left(\sum \mathrm{E}_{\mathrm{a}}-\sum \mathrm{E}_{\mathrm{im}}-\sum \mathrm{E}_{\mathrm{sh}}\right),
$$

where $E_{h}$ is the energy accumulated in the economically useful part of the crop of plants or animal products, $\mathrm{J} / \mathrm{t}$;

$\mathrm{E}_{\mathrm{im}}$ - part of the total energy spent on all imported means of production for the production of this economically useful part of plants or animals, $\mathrm{J} / \mathrm{t}$; $\mathrm{J} / \mathrm{t}$.

$\mathrm{E}_{\mathrm{sh}}$ - natural energy (solar, wind, biomass energy, etc.) used in the technological process,

The inclusion of the $\mathrm{E}_{\mathrm{im}}$ in the formula is of purely methodological importance, since in practical calculations this component does not need to be calculated and determined. But the total energy costs for equipment for the use of renewable energy sources created within the state must be taken into account when calculating the Ea.

For the purposes of the national assessment of the efficiency of energy saving, it is no longer possible to neglect the accuracy of calculations of the energy embodied in machines and equipment (technological lines), since the calculations will distort the real efficiency of the total energy use and lead to erroneous conclusions and management decisions..

However, the determination of the energy intensity of individual types of agricultural products is complicated by the fact that, firstly, the process of its production is mediated by intersectoral links; secondly, at similar stages of the technological cycle, various machines and equipment with different energy intensity parameters are used; thirdly, most machines are involved in the production of several agricultural products (energy storage). 
For the calculation of energy equivalents, it is advisable to use the following approach: the specific energy costs Ea for the production of i-th type of machinery or equipment, energy resources and inventory for $\mathrm{d}$-th machine-building enterprise

$$
\varepsilon_{\mathrm{di}}=\left(\sum \mathrm{M}_{\mathrm{ki}} \varepsilon_{\mathrm{ki}}+\sum \mathrm{E}_{\mathrm{si}}+\sum \mathrm{E}_{\mathrm{si}} \varepsilon_{\mathrm{si}}+\sum \mathrm{E}_{\mathrm{Ti}}+\sum \mathrm{E}_{\mathrm{wi}} \varepsilon_{\mathrm{wi}}\right) / \sum \mathrm{M}_{\mathrm{i}} \mathrm{N}_{i}, \mathrm{~J} / \mathrm{T}
$$

where $\mathrm{M}_{\mathrm{ki}}$ is the mass of $\mathrm{k}$-th materials and purchased items (units) for the production of the annual volume of $i$-th machine or equipment, tons;

$\varepsilon_{\mathrm{K}}$ - is the energy equivalent of $\mathrm{k}$-th materials and purchased items( units), $\mathrm{J} / \mathrm{t}$;

$\sum \mathrm{E}_{\mathrm{si}}$ - the sum of energy costs of s-th energy carriers (electricity, fuel, heat) in the production of $i$-th equipment, $\mathrm{J}$;

$\mathcal{E}_{\mathrm{s}}$ - energy equivalent of s-th energy carriers, $\mathrm{J} / \mathrm{t}$ -

$\sum E_{\mathrm{wi}}$ - the energy of the living labor of the employees of the enterprise in the production of the i-th machine or equipment, J;

$\mathcal{E}_{\mathrm{sf}}$ - - energy equivalent of the energy of living labor of f-th workers, $\mathrm{J} /$ person-hour;

$\mathrm{M}_{\mathrm{i} i}$ - mass of the $\mathrm{i}$-th machine or equipment, $\mathrm{t}$;

$\mathrm{N}_{i-}$ is the number of machines or equipment produced per year at the d-th enterprise,

and the components of the formula (8) can be increased depending on the types and amount of other resources used in the production processes.

The cost of past energy embodied in r-type buildings can be calculated using the formula

$$
\mathrm{E}_{\mathrm{br}}=\sum \mathrm{V}_{\mathrm{br}} \mathrm{N}_{\mathrm{br}} \varepsilon_{\mathrm{R}}
$$

where $\mathrm{V}_{\mathrm{br}}$ is the volume of the building, $\mathrm{m}^{3}$;

$\mathrm{N}_{\mathrm{br}}$ - number of r-type buildings, pcs;

$\varepsilon_{\mathrm{R}}$-energy equivalent of an $\mathrm{r}$-type building (calculated according to the same principle as $\mathrm{c}(8), \mathrm{MJ} / \mathrm{m}^{3}$.

In turn, the value of the total energy consumption of Ea is obtained by (10):

$$
\mathrm{Ea}=\left(\sum \mathrm{E}_{\mathrm{dsp}}+\sum \mathrm{E}_{\mathrm{dsp}} \mathrm{x} \boldsymbol{\varepsilon}_{\mathrm{s}}+\sum \mathrm{E}_{\mathrm{wvx}}+\sum \mathrm{E}_{\mathrm{wvx}} \boldsymbol{\varepsilon}_{\mathrm{wv}}+\sum \mathrm{E}_{\mathrm{br}}+\sum \alpha\left(\sum\left(\mathrm{M}_{\mathrm{ip}} \mathrm{x} \varepsilon_{\mathrm{di}}\right) / \mathrm{t},\right.\right.
$$

where $E_{\mathrm{dsp}}$ is the direct energy consumption of s-th energy carriers in the process of cultivation of the $\mathrm{p}$-th crop (production of $\mathrm{p}$-th agricultural products), $\mathrm{j}$;

$\mathcal{E}_{\mathrm{s}}$ - energy equivalent of s-th energy carriers, $\mathrm{J} / \mathrm{t}$;

$\mathrm{E}_{\mathrm{wvx}}$ - energy consumption of live labor of $\mathrm{v}$-th workers in the production process of agriculture, $\mathrm{J}$;

$\varepsilon_{\mathrm{wv}}$ - energy equivalent of the energy of live labor spent in the production of agricultural products, $\mathrm{J} / \mathrm{J}$;

$\alpha$ - the fraction of time in the year that the machine is occupied on the i-th crop;

$\mathrm{t}$ - the service life of the machine (equipment, building). In contrast to economic calculations, where $t$ is set by standards (depreciation periods), energy calculations take into account the actual service life of the machine (equipment, buildings, etc.) before write-off;

$\mathrm{M}_{\mathrm{ip}}$ - the mass of $\mathrm{i}$-th machines and equipment involved in the production process of $\mathrm{r}$-th agricultural products, $\mathrm{J}$

$\varepsilon_{\mathrm{di}}$ - the specific energy costs Es for the production of the i-th type of machinery or equipment, obtained by (8).

The energy costs embodied in the energy carriers of the s-th type are calculated by the formula

$$
\mathrm{E}_{\mathrm{f.s}}=\sum \mathrm{q}_{\mathrm{i}} \times \mathrm{t}_{\mathrm{i}} \times \mathrm{T}_{\mathrm{i}} \times \boldsymbol{E}_{\mathrm{fsi}} \text {, }
$$

where $\mathrm{q}_{\mathrm{i}}$ is the hourly consumption of s-that type of fuel by $\mathrm{i}$-that machine, $\mathrm{kg} / \mathrm{h}$;

$t_{i}$ - the daily working time fund of the $i$-th machine or equipment;

$\mathrm{T}_{\mathrm{i}}$ - the number of days of operation of the $\mathrm{i}$-th machine or equipment in the year, days; 
$\mathcal{E}_{\mathrm{fsi}}$ - ' nergetic equivalent of the s-type of fuel (energy carrier) of the i-machine, $\mathrm{J} / \mathrm{kg}$

To calculate the amount of energy accumulated in agricultural products, the following expression can be used:

$$
\mathrm{E}_{\mathrm{h}}=\mathrm{E}_{\mathrm{p}} \mathrm{F}_{\mathrm{p}} \lambda_{\mathrm{p}}\left[\left(\mathrm{x}_{\mathrm{hp}}-\sum \alpha_{\mathrm{p}}\right)+\alpha_{\mathrm{p} 2} \delta_{\mathrm{p}} \mathrm{x}_{\mathrm{c}}+\alpha_{\mathrm{p} 2} \delta_{\mathrm{p}} \mathrm{k}_{\mathrm{m}} \mathrm{k}_{\mathrm{g}}+\alpha_{\mathrm{p} 3} \mathrm{k}_{1}\right]
$$

where $E_{p}$ is the arrival of solar radiation per unit area of arable land occupied by the $p$-th crop, $\mathrm{MJ} / \mathrm{ha}$;

$F_{p}$ - the area occupied by the $p$-th culture, ha;

$\lambda_{\mathrm{p}}$-photosynthesis coefficient ;

$x_{\mathrm{hp}}$ - the yield coefficient of the economically useful part of the crop of the given crop;

$\alpha_{p}$ - the share of the use of the crop of the p-th crop for non-food purposes (ap 1 - residues in the field, ap2 - feed, ap3-biofuels, etc. $)(\operatorname{ap} 1+$ ap $2+$ ap $3+\ldots+$ apn $=1)$;

$\delta p-$ coefficient of conversion of feed energy from r-th plants to energy of animal products;

$x c$ - the share of losses of livestock products during processing into food products;

$\mathrm{k}_{\mathrm{m}}$ - the yield coefficient of organic animal waste products;

$\mathrm{k}_{\mathrm{g}}$ - coefficient of biogas energy output;

$\mathrm{k}_{1}$ - is the coefficient of loss of biomass energy in the production of biofuels

The method of calculating energy equivalents is a complex, long and expensive process that requires not only a thorough approach, but also access to the source information of hundreds of enterprises, since it is necessary to know exactly the energy costs for each type of raw material and for all stages of processing to the final product. Such work is available only to large research teams. Therefore, it is important for scientific institutions to carry out serious work to clarify energy equivalents and only then apply the methods of energy economic assessment for making management decisions or use them for research purposes.

\section{Conclusion}

The method of calculating energy equivalents is a complex, long and expensive process that requires not only a thorough approach, but also access to the source information of hundreds of enterprises, since it is necessary to know exactly the energy costs for each type of raw material and for all stages of processing to the final product. Such work is available only to large research teams. Therefore, it is important for scientific institutions to carry out serious work to clarify energy equivalents and only then apply the methods of energy economic assessment for making management decisions or use them for research purposes.

Conclusions. The article shows a conceptual approach to the methodology of energyeconomic assessment of agricultural technologies and projects. The main advantage of the energy-economic assessment is that its application makes it possible to compare in single units of measurement (regardless of the historical period or the state, the current market situation, currency volatility) the costs of cultivation of plants or production of livestock products with the results of production and is mainly of national strategic importance. It is on the basis of such justification that state structures can develop economic guidelines and incentives for the introduction of new energy-efficient technologies, machines and projects, including the use of renewable energy sources.

To ensure the reliability of the energy-economic assessment in connection with the constant technological and organizational changes and the digitalization of technology and the economy, it is necessary to continue research in the direction of improving, refining and regularly updating energy equivalents. 


\section{References}

1. Energy efficiency in agriculture (AGREED), project, FP7-KBBE-2011-5-289139, http://www.agree.aua.gr

2. N. Pelletier, E. Adsley, S. Brodt et al., Agriculture and food (2011) doi: 10/1146//annurev-environ-0817110-161014

3. International Energy Agency (2014) energy-efficiency-indicators-essentials-for-policymaking-russian-version.html

4. N. Pelletier, E. Audsley, T. Garnett, Annual Review of Environment and Resources 36(1) (2011) DOI:10.1146 / annurev-environ-081710-161014

5. J. Ehrche-Pasteur, E. Loiseocaro, S. Arnaud Ely, Agronomy for Sustainable Development Review 40(4) (2020) DOI: 10.1007/s13593-020-00627-2

6. J. Vítor, Energy 103, 543-556 (2016) DOI: 10.1016/j. energy. 2016. 03. 017

7. F. Rilong, L. Boqiang, Technological Forecasting and Social Change 109 (2016) DOI: 10.1016/j. techfore. 2016. 05. 012

8. J. Woods, A. Williams, J.K. Hughes et al., Biological Sciences 365(1554), 2991 - 3006 (2010)

9. B.W. Ang, X.Y. Xu, B. Su, Energy Economics, 47, 68-76 (2015)

10. M. Beltrán-Esteve, A.J. Picazo-Tadeo, Energy Policy 104, 240-252 (2017)

11. Electro Information Technology (EIT), 2016 IEEE International Conference, 0510-0515 (2016)

12. L.G. Smith, A.G. Williams, B.D. Pierce, Cambridge (2014) DOI: https://doi.org/10.1017/S17421705130004717

13. J. Qin, H. Tao et al., Xinjiang Uygur Autonomous Region, China 12, 1089 (2020)

14. Energy Efficiency Indicators for 2019. Statistical Report-December 2019 IEA Statistical Manual on Energy Efficiency Indicators, http://data.iea.org/ 